\title{
Forehead is as sensitive as finger pulse oximetry during general anesthesia
}

\author{
[Pendant l'anesthésie générale, les mesures de sphygmo-oxymétrie prises sur le front
}

ou le doigt sont comparables]

Shigekazu Sugino MD, Noriaki Kanaya MD PhD, Masahito Mizuuchi MD, Masayasu Nakayama MD PhD, Akiyoshi Namiki MD PhD

Purpose: To compare the performance of a forehead probe to a conventional finger pulse oximetry probe in anesthetized patients.

Methods: Eighteen patients participated in the study. Each probe was connected to a Nellcor N-550 pulse oximeter. Anesthesia was induced and maintained with propofol. After intubation, the patients received air to achieve a steady-state of peripheral arterial oxygen saturation $\left(\mathrm{SpO}_{2}\right)$. Ventilation was interrupted to induce a hypoxic state. As soon as one of the two $\mathrm{SpO}_{2}$ 's decreased to $90 \%$, the patients' lungs were ventilated with 100\% oxygen. To evaluate the performance of the two pulse oximeters, time to the lowest $(T L)$, time of recovery (TR) and lag times to beginning of $\mathrm{SpO}_{2}$ decrease (Lag) were measured.

Results: There were no significant differences in $T L$ and $T R$ between forehead and finger pulse oximetry under normal perfusion conditions during general anesthesia. When the axillary artery was compressed to mimic reduced peripheral perfusion, $\mathrm{SpO}_{2}$ in the forehead decreased sooner than in the finger during hypoxia. The forehead and finger TLs were similar, however, TR was significantly longer in the finger.

Conclusion: The forehead $\mathrm{SpO}_{2}$ sensor can be used as an alternative to the conventional finger sensor during general anesthesia.

Objectif: Comparer la performance d'un capteur frontal et d'un capteur traditionnel au doigt chez des patients anesthésiés.

Méthode : Dix-huit patients ont participé à l'étude. Chaque capteur a été relié à un sphygmo-oxymètre Nellcor N550. L'anesthésie a été induite et maintenue avec du propofol. Après l'intubation, les patients ont reçu de l'air pour l'obtention d'un état d'équilibre de la saturation en oxygène du sang artériel périphérique $\left(\mathrm{SpO}_{2}\right)$. La ventilation a été interrompue pour induire un état hypoxique. Aussitôt qu'une ou l'autre mesure de $\mathrm{SpO}_{2}$ baissait à $90 \%$, les patients étaient ventilés avec de l'oxygène à $100 \%$. La performance des deux appareils a été mesurée par le temps nécessaire pour obtenir la plus basse valeur de $\mathrm{SpO}_{2}$ (TB), le temps nécessaire à la récupération (TR) et les intervalles précédant les baisses de $\mathrm{SpO}_{2}$ (Int).

Résultats : Il n'y a pas eu de différences significatives de TF et TR entre les résultats notés au front et au doigt dans des conditions normales de perfusion pendant l'anesthésie générale. Quand l'artère axillaire était compressée pour imiter une perfusion périphérique réduite, la $\mathrm{SpO}_{2}$ diminuait plus vite au front qu'au doigt pendant l'hypoxie. Les TF au front et au doigt ont été similaires, mais le TR a été significativement plus long au doigt.

Conclusion : Le capteur frontal de $\mathrm{SpO}_{2}$ peut remplacer un capteur traditionnel fixé au doigt pendant l'anesthésie générale.

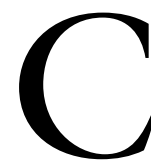

ONTINUOUS monitoring of peripheral arterial oxygen saturation $\left(\mathrm{SpO}_{2}\right)$ via pulse oximetry has been standard and essential practice in the operating room, intensive care unit, general ward and elsewhere. ${ }^{1}$ The use of pulse oximetry is associated with an improved ability to detect hypoxia in the course of perioperative patient care. Reports about the accuracy and reliability of pulse oximetry are numerous, and the method is widely accepted. However, several studies have found inaccuracies and site-dependent differences under special circumstances such as peripheral vasoconstriction, decreased cardiac output, hypothermia, elevated or dependent limb position, venous engorgement, and regional anesthesia. ${ }^{2}$

Recently, a unique oximeter probe $\left(\right.$ Max-fast $^{\mathrm{TM}}$, Tyco Healthcare Nellcor Puritan Bennett Division, CA, USA), which can measure $\mathrm{SpO}_{2}$ on the forehead, has been developed. Because the forehead blood flow

From the Department of Anesthesiology, Sapporo Medical University School of Medicine, Sapporo, Japan.

Address correspondence to: Dr. Noriaki Kanaya, Department of Anesthesiology, Sapporo Medical University School of Medicine, S-1,

W-16, Chuo-ku, Sapporo 060-8543, Japan. Phone: +81-11-611-2111; Fax: +81-11-631-9683; E-mail: kanaya@sapmed.ac.jp

Accepted for publication October 16, 2003.

Revision accepted February 18, 2004. 
is nearer to the heart than the fingertip, it is expected that the forehead probe may detect hypoxia more quickly. We undertook this study to examine whether forehead oximetry can detect hypoxia more quickly than fingertip oximetry during general anesthesia.

\section{Materials and methods}

The institutional Ethics Committee at Sapporo Medical University approved this study, and all 18 participants [American Society of Anesthesiologists (ASA) physical status I] granted their written informed consent. All were non-smokers and had no neurological, cardiovascular or respiratory disease.

We tested two disposable adhesive pulse oximeter sensors: the Nellcor D-25 (Max-A ${ }^{\mathrm{TM}}$, Tyco Healthcare Nellcor Puritan Bennett Division, CA, USA) and the Nellcor forehead sensor (Max-fast ${ }^{\mathrm{TM}}$, Tyco Healthcare Nellcor Puritan Bennett Division, CA, USA). The Max$\mathrm{A}^{\mathrm{TM}}$ was placed on the index finger of the patient's right hand. The Max-Fast ${ }^{\mathrm{TM}}$ was attached to the patient's forehead above the right eyebrow (Figure 1). Noninvasive blood pressure was measured with a cuff on the opposite arm. Anesthesia was induced and maintained with propofol $\left(3 \mathrm{mg} \cdot \mathrm{kg}^{-1} \cdot \mathrm{hr}^{-1} i v\right)$. Tracheal intubation was facilitated with vecuronium $0.1 \mathrm{mg} \cdot \mathrm{kg}^{-1} \mathrm{iv}$. Ventilation was controlled mechanically to maintain normocapnia. Each probe was connected to a Nellcor N-550 pulse oximeter (Tyco Healthcare Nellcor Puritan Bennett Division, CA, USA). Both sensors were optically shielded from room light. $\mathrm{SpO}_{2}$ and pulse rate (PR) were recorded continuously using a bedside computer system. The room temperature was maintained at 23 to $25^{\circ} \mathrm{C}$ during the operation.

After intubation, the fraction of inspiratory oxygen $\left(\mathrm{FIO}_{2}\right)$ was reduced to 0.21 while hemodynamic conditions remained stable. Then, mechanical ventilation was stopped until one of the two $\mathrm{SpO}_{2}$ 's decreased to $90 \%$. As soon as the $\mathrm{SpO}_{2}$ became $90 \%$, the lungs were ventilated with $100 \%$ oxygen.

Next, the $\mathrm{FIO}_{2}$ was decreased to 0.21 again and maintained at this level for ten minutes or until a steady state was achieved. The axillary artery of the patient's right arm was compressed with a tennis ball to reduce peripheral perfusion in the finger. Likewise, we disconnected the endotracheal tube from the ventilator and stopped ventilation until either of the two sensors indicated the $\mathrm{SpO}_{2}$ had dropped to $90 \%$. As soon as the $\mathrm{SpO}_{2}$ became $90 \%$, the lungs were ventilated with $100 \%$ oxygen.

To evaluate the performance of the two pulse oximeters, we measured the time required for $\mathrm{SpO}_{2}$ to fall to its lowest value (TL), time for recovery to baseline (TR), and lag time [time between the beginning

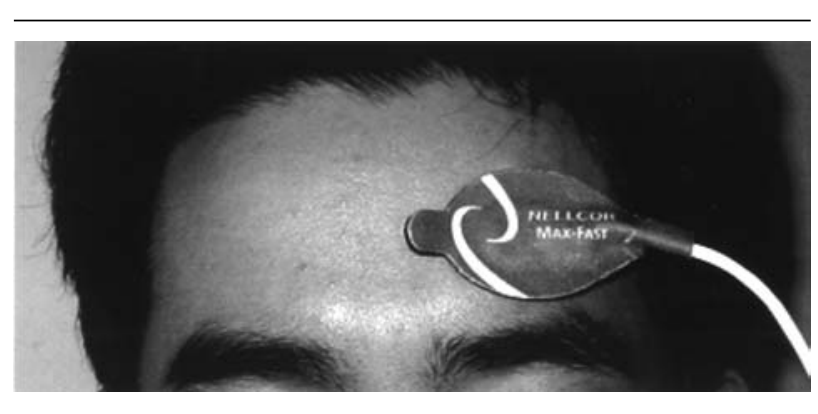

FIGURE 1 Forehead sensor (Max-fast ${ }^{\mathrm{TM}}$ ) attached to the patient's forehead.

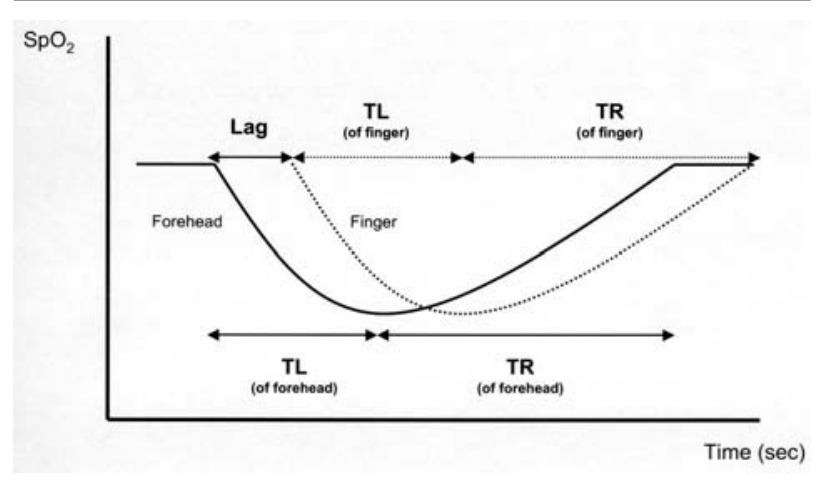

FIGURE 2 Five variables were defined: Lag, TL (forehead), TL (finger), TR (forehead) and TR (finger). Lag = the lag time (time between the beginning of $\mathrm{SpO}_{2}$ decrease as monitored by the forehead sensor and the beginning of $\mathrm{SpO}_{2}$ decrease as monitored by the fingertip sensor); $\mathrm{TL}=$ time to reach the lowest $\mathrm{SpO}_{2}$ values; and TR = time to recovery to baseline.

of $\mathrm{SpO}_{2}$ decrease (monitored by one sensor) and the beginning of $\mathrm{SpO}_{2}$ decrease (monitored by the second sensor)]; (Lag); (Figure 2). Forehead and finger measures were accordingly designated TL (forehead), TL (finger), TR (forehead) and TR (finger). Baseline PR was measured before mechanical ventilation was stopped. In a preliminary trial, three patients had an arterial catheter (a 22-gauge cannula) placed in the radial artery of the arm opposite the cuff. One-millilitre samples of arterial blood were drawn at steady state and when $\mathrm{SpO}_{2}$ values decreased to $90 \%$. Both samples were processed using a blood gas analyzer (M860-CO oximeter, Chiron Diagnostics, CA, USA). When the arterial blood saturation $(99 \% \pm 1 \%$ and $88 \%$ $\pm 1 \%$ during control and desaturation, respectively) 


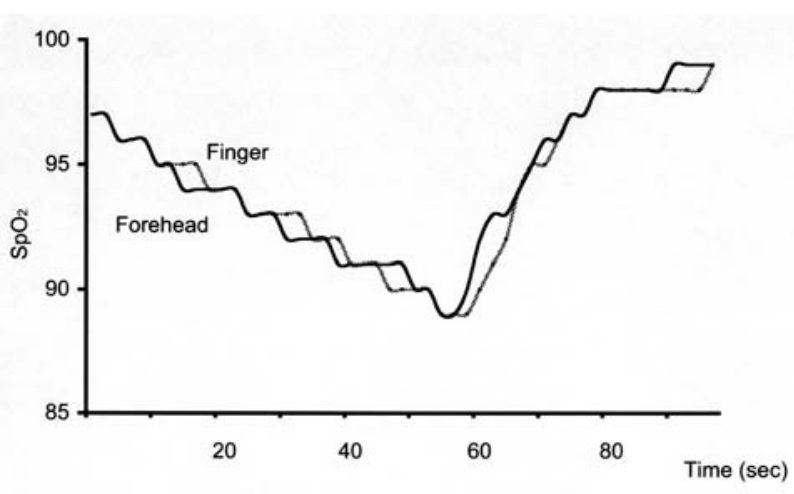

FIGURE 3 Typical trace under normal conditions. Solid line is the forehead $\mathrm{SpO}_{2}$. Dotted line is the finger $\mathrm{SpO}_{2}$. Two $\mathrm{SpO}_{2}$ values are parallel, lag time is a few seconds.

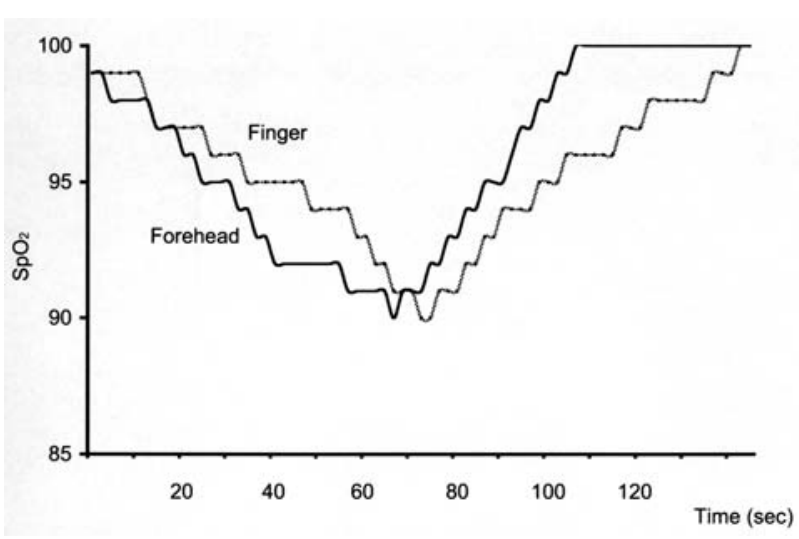

FIGURE 4 Typical trace with simulated low peripheral perfusion. Solid line is the forehead $\mathrm{SpO}_{2}$. Dotted line is the finger $\mathrm{SpO}_{2}$. Forehead $\mathrm{SpO}_{2}$ decreased sooner and recovered earlier than finger $\mathrm{SpO}_{2}$.

was shown to be equal to finger $\mathrm{SpO}_{2}(99 \% \pm 1 \%$ and $89 \% \pm 1 \%$ during control and desaturation, respectively), arterial cannulation was no longer performed. The data from these three patients were not included in the present study.

\section{Statistical analysis}

All data are presented as mean $\pm \mathrm{SD}$. If the forehead $\mathrm{SpO}_{2}$ started to decrease sooner than finger $\mathrm{SpO}_{2}$, lag time is presented as a positive number. Conversely, if finger $\mathrm{SpO}_{2}$ started to decrease sooner, lag time is presented as a negative number. In a previous report, ${ }^{3}$ lag times between forehead and finger sensors were more than $60 \mathrm{sec}$ in awake healthy volunteers during low perfusion. Therefore, $n=4$ subjects would be necessary to detect such a difference if $\alpha=0.05$ and $B=0.1$. The forehead and finger $\mathrm{SpO}_{2}$ 's were compared with the use of paired Student's $t$ tests. In addition, lag times under normal and low perfusion conditions were compared with the use of paired Student $t$ tests. A $P$ value of $<0.05$ was considered statistically significant.

\section{Results}

There were seven males and 11 females. The average age of the patients was $51 \pm 14 \mathrm{yr}$, weight $60 \pm 8 \mathrm{~kg}$, height $168 \pm 8 \mathrm{~cm}$. Figure 3 shows a typical trace under normal conditions. The $\mathrm{SpO}_{2}$ 's monitored by the finger and forehead sensors parallel each other, and lag time is a few seconds. Figure 4 shows a typical trace during low peripheral perfusion. The forehead $\mathrm{SpO}_{2}$ 's decreases before finger $\mathrm{SpO}_{2}$. The Table summarizes the results both under normal and simulated low peripheral perfusion conditions. The PRs for the two conditions did not differ significantly. The forehead and finger measurements of TL and TR under normal perfusion conditions did not differ significantly, nor did the forehead and finger measurements of TL during low perfusion. However, the difference between forehead and finger TR under peripheral low perfusion conditions was significant $(P=0.0054)$. In 14 patients, the forehead $\mathrm{SpO}_{2}$ decreased before the corresponding finger $\mathrm{SpO}_{2}$ during simulated low peripheral perfusion. Lag times under normal and low peripheral perfusion conditions $(0.9 \pm 5.7 \mathrm{sec}$ vs $6.3 \pm 4.9 \mathrm{sec}$, respectively $)$ were significantly different $(P=0.0039)$.

\section{Discussion}

Pulse oximetry provides an easy-to-use, highly accurate, relatively inexpensive, method to continuously monitor for hypoxia. However, past studies have demonstrated a $7 \%$ to $9 \%$ failure rate with conventional pulse oximetry. ${ }^{4,5}$ In most clinical settings, the pulse oximeter continuously monitors oxygen saturation levels but, in some settings, various factors (e.g., severe hypotension, low perfusion, or shivering due to hypothermia) interfere with accurate measurement. ${ }^{2}$ Because these factors disrupt peripheral circulation, finger $\mathrm{SpO}_{2}$ can be abnormal.

Alternatively, the pulse oximetry sensor can be located on the nose, the ear or on the buccal mucosa ${ }^{6,7}$ but these devices are not popular. Clayton $e t$ al. found that only ear probes can be used, though with risk of a higher "drop out" rate, during poor perfusion. ${ }^{6}$ More recently, a better adhesive forehead reflectance sensor has been developed. This sensor has 
TABLE Characteristics of forehead and finger $\mathrm{SpO}_{2}$ monitoring during a decrease of $\mathrm{SpO}_{2}$ to $90 \%$

\begin{tabular}{lllllll}
\hline & PR (beats. $\left.\mathrm{min}^{-1}\right)$ & \multicolumn{2}{c}{ TL (sec) } & \multicolumn{2}{c}{ TR (sec) } & \multicolumn{2}{c}{ Lag (sec) } \\
& & forehead & finger & forehead & finger & \\
\hline Normal & $74 \pm 8$ & $42.9 \pm 15.3$ & $40.1 \pm 14.9$ & $30.8 \pm 15.3$ & $31.2 \pm 11.7$ & $0.9 \pm 5.7$ \\
Low perfusion & $74 \pm 9$ & $44.9 \pm 14.3$ & $42.6 \pm 16.1$ & $34.5 \pm 13.8$ & $49.2 \pm 23.1^{*} \dagger$ & $6.3 \pm 4.9 \dagger$ \\
\hline
\end{tabular}

Values are mean \pm SD. Low perfusion condition was simulated by compressing the axillary artery to reduce peripheral perfusion in the finger. $\mathrm{PR}=$ pulse rate; $\mathrm{TL}=$ time until $\mathrm{SpO}_{2}$ reached its minimal value; $\mathrm{TR}=$ time until $\mathrm{SpO}_{2}$ recovered to the corresponding baseline level from its minimal value; $\mathrm{Lag}=\mathrm{lag}$ time from the time one $\mathrm{SpO}_{2}$ value began to decrease until the time the other $\mathrm{SpO}_{2}$ value began to decrease. ${ }^{*} P<0.01$ vs forehead sensor. $\dagger P<0.01$ vs normal perfusion condition.

higher sensitivity than that of conventional fingertip pulse oximeter sensors when used on healthy volunteers under low perfusion conditions. ${ }^{3}$ However, this forehead probe has not been compared clinically with conventional probes.

In the present study, the TL and TR of both sensors were almost identical under normal conditions. In addition, lag time was nearly zero seconds. Therefore, forehead $\mathrm{SpO}_{2}$ is as useful clinically for detecting hypoxia as finger $\mathrm{SpO}_{2}$ when peripheral circulation is well maintained. In contrast, during low perfusion, TR (finger) was approximately $15 \mathrm{sec}$ longer than TR (forehead). Moreover, lag time was longer under low perfusion compared to normal conditions. These findings indicate that forehead $\mathrm{SpO}_{2}$ sensors may be more sensitive to hypoxia than finger $\mathrm{SpO}_{2}$ sensors during low peripheral perfusion.

Errors in monitoring can occur because of human error or technical failure. Though human error cannot be eliminated, incorrect monitoring (especially delayed detection of hypoxia) can be lethal and should be minimized. Pulse oximeters that generate reliable data rapidly represent a significant improvement in patient monitoring. The most important characteristic of a pulse oximeter is its ability to identify all episodes of hypoxia to permit intervention before the development of clinically significant hypoxia. In this study, the forehead $\mathrm{SpO}_{2}$ sensor was able to detect the development of hypoxia earlier than the finger $\mathrm{SpO}_{2}$ sensor under simulated low peripheral perfusion conditions. However, it could be argued that the difference in $\mathrm{SpO}_{2}$ levels was clinically irrelevant.

We recognize several limitations of our study. First, the TL for the two probes was almost identical in both experiments. Because the TL means the time required for $\mathrm{SpO}_{2}$ to fall to its lowest values, lag time should be considered to evaluate a 'real' TL. Moreover, we did not measure the time to $\mathrm{SpO}_{2}=90 \%$ with both probes to avoid excessive hypoxia. Therefore, the sensitivity of the forehead $\mathrm{SpO}_{2}$ probe might be underestimated as compared to that of the finger $\mathrm{SpO}_{2}$ probe. In fact, forehead $\mathrm{SpO}_{2}$ started to decrease faster than finger $\mathrm{SpO}_{2}$ under normal and low perfusion conditions. Second, we did not test subjects with cold extremities, systemic hypotension or shock. For ethical reasons, we could not test pulse oximeters during a hypoxic challenge at ambient temperatures of 16 to $18^{\circ} \mathrm{C}$ to reduce peripheral perfusion. ${ }^{8-10}$ Alternatively, the axillary artery was compressed to decrease perfusion. Weber et al. occluded the brachial artery, ${ }^{11}$ and Gerhring et al. used an inflatable balloon impinging on the brachial artery ${ }^{12}$ for the same purpose. Third, the present study did not determine performance of the devices (specially the forehead sensor) under conditions of systemic hypoperfusion/ low cardiac output. It also does not demonstrate the reliability and performance of the forehead pulse oximeter probes for saturations below $90 \%$.

In summary, forehead $\mathrm{SpO}_{2}$ monitoring, in the range $\mathrm{SpO}_{2}=90 \%$ to $100 \%$, has a sensitivity similar to conventional finger monitoring under normal conditions during general anesthesia. The use of forehead $\mathrm{SpO}_{2}$ sensors may improve $\mathrm{SpO}_{2}$ monitoring, especially in patients in whom $\mathrm{SpO}_{2}$ cannot be measured at the finger.

\section{References}

1 Aoyagi T, Miyasaka K. Pulse oximetry: its invention, contribution to medicine, and future tasks. Anesth Analg 2002; 94: S1-3.

2 Clayton DG, Webb RK, Ralston AC, Dutbie D, Runciman $W B$. A comparison of the performance of 20 pulse oximeters under conditions of poor perfusion. Anaesthesia 1991; 46: 3-10.

3 Bebout DE, Mannheimer PD, Wun CC. Site-dependent differences in the time to detect changes in saturation during low perfusion. Crit Care Med 2001; 29: Al15 (abstract).

4 Moller JT, Pedersen T, Rasmussen LS, et al. Randomized evaluation of pulse oximetry in 20,802 patients: I. 
Design, demography, pulse oximetry failure rate, and overall complication rate. Anesthesiology 1993; 78:

436-44.

5 Reich DL, Timcenko A, Bodian CA, et al. Predictors of pulse oximetry data failure. Anesthesiology 1996; 84: 859-64.

6 Clayton DG, Webb RK, Ralston AC, Duthie D, Runciman WB. Pulse oximeter probes. A comparison between finger, nose, ear and forehead probes under conditions of poor perfusion. Anaesthesia 1991; 46: 260-5.

7 O'Leary RJ Jr, Landon M, Benumof JL. Buccal pulse oximeter is more accurate than finger pulse oximeter in measuring oxygen saturation. Anesth Analg 1992; 75: 495-8.

8 Shab N, Clack SL, Hoang TD. Is there a difference in recovery time for the accurate display of oxygen saturation $\left(\mathrm{SpO}_{2}\right)$ and pulse rate $(\mathrm{PR})$ after motion induced failure of pulse oximeters (PO) during low perfusion and normoxemia or hypoxemia in human volunteers? Anesthesiology 2001; 95: A552 (abstract).

9 Clack SL, Shah N, Hoang TD, Gupta B. A comparison of four major brands of pulse oximeters (PO) with Masimo SET (PO) during motion and low perfusion under normoxic and hypoxic conditions in human volunteers. Anesthesiology 2001; 95: A586 (abstract).

10 Shah N, Hoang TD, Clack SL, Anderson CT. The impact of motion and low perfusion on the performance of Masimo SET pulse oximeter (PO) and four other POs for measurement of oxygen saturation $\left(\mathrm{SpO}_{2}\right)$ and pulse rate $(\mathrm{PR})$ in human volunteers. Anesthesiology 2001; 95: A553 (abstract).

11 Weber WM, Elfadel IM, Barker SJ. Low-perfusion resistant pulse oximetry. J Clin Monit 1995; 11: 284.

12 Gebring H, Hornberger C, Matz H, Konecny E, Schmucker $P$. The effects of motion artifact and low perfusion on the performance of a new generation of pulse oximeters in volunteers undergoing hypoxemia. Respir Care 2002; 47: 48-60. 